E. А. Жигалова. Мягкие навыки в профессиональной деятельности сотрудников правоохранительных органов

\author{
Научная статья \\ УДК 351.74 \\ DOI: $10.18101 / 2307-3330-2021-1-65-70$
}

\title{
МЯГКИЕ НАВЫКИ В ПРОФЕССИОНАЛЬНОЙ ДЕЯТЕЛЬНОСТИ СОТРУДНИКОВ ПРАВООХРАНИТЕЛЬНЫХ ОРГАНОВ
}

\author{
(C) Жигалова Евгения Александровна \\ научный сотрудник научно-исследовательского \\ и редакционно-издательского отдела, \\ Восточно-Сибирский институт МВД России \\ Россия, 664074, г. Иркутск, ул. Лермонтова, 110 \\ razr15@rambler.ru
}

\begin{abstract}
Аннотация. В современных реалиях исполнение профессиональных обязанностей требует не только определенных знаний, которые свойственны определенной профессии, но и навыков, которые позволяют наиболее эффективно использовать собственный опыт. Владение мягкими навыками имеет особую значимость для специалистов во всех областях, в том числе и для сотрудников правоохранительных органов. В статье рассматриваются понятие и виды мягких навыков, их значение и область применения. Отдельно рассматриваются факторы применения навыков soft skills в работе сотрудников правоохранительных органов.

Ключевые слова: твердые навыки (hard skills), мягкие навыки (soft skills), профессиональные компетенции, профессиональная деятельность, личные качества.
\end{abstract}

\section{Для цитирования}

Жигалова Е. А. Мягкие навыки в профессиональной деятельности сотрудников правоохранительных органов // Вестник Бурятского государственного университета. Образование. Личность. Общество. 2021. Вып. 1. С. 65-70.

В условиях цифровой экономики, характеризующейся активным внедрением цифровых технологий и распространением новых информационных систем, увеличивается напряженность труда и повышаются требования к эффективности. Это требует от экономики не только гуманизации трудовой деятельности, но и уточнения актуальных компетенций. Направленность на достижение принципиальных для общества задач повышает значимость профессиональной подготовки, а для этого необходимо развитие различных навыков.

Сами навыки можно разделить на две большие категории: твердые (hard skills) и мягкие, иногда гибкие (soft skills). Развитие первых можно наблюдать, а их результат - измерить и наглядно продемонстрировать. К ним относят умение решать математические задачи, читать, изучать иностранные языки и т. д. То есть владение твердыми навыками подразумевает использование каких-либо конкретных знаний, которые необходимы для осуществления конкретной деятельности.

В то же время мягкие навыки отвечают за социализацию, которая в последние годы стала играть более значительную роль, чем раньше. В отличие от жестких, их развитие измерить не так просто, но именно они помогают наиболее эф- 
фективно продемонстрировать hard skills и применять их на практике. Более того, мягкие навыки универсальнее, поэтому они будут полезны независимо от вида деятельности.

В целом Soft Skills - это собирательный термин, который ссылается на множество вариантов поведения, помогающих людям в работе, в частности командной, а также успешно социализироваться. То есть мягкие навыки - это комплекс неспециализированных, надпрофессиональных навыков, которые отвечают за успешное участие в рабочем процессе, высокую производительность и, в отличие от специализированных навыков, не связаны с конкретной сферой.

Анализ работ современных исследователей доказывает, что все чаще в профессиональной деятельности отдается преимущество наличию soft skills. Для coвременных профессионалов актуальными являются:

- личные качества (коммуникабельность, умение слушать, честность и этичность, умение управлять человеческими ресурсами, смелость идти на разумный риск и говорить правду руководству, позитивность и преданность делу, аналитические способности, умение мыслить критично, креативность, гибкость, амбициозность, лидерство, стрессоустойчивость);

- мотивация, в частности самомотивация;

- работа с командой и в команде, развитие взаимоотношений.

О. Л. Чуланова [8] считает, что в состав soft skills должны входить: способность строить межкультурные сетевые коммуникации (социальные и профессиональные), учиться и самосовершенствоваться и т. п. Исследователи [3] считают, что в условиях цифровой экономики кадры должны владеть такими навыками:

- логическое и креативное мышление;

- умение решать проблемы;

- вербальная грамотность;

- готовность получать новый опыт;

- готовность к компромиссам;

- навыки межличностного общения и т. п.

Вообще большая часть навыков, используемых для достижения цели, - это soft skills. И чем выше сотрудник поднимается по карьерной лестнице, тем более важную роль играют именно социальные навыки, в то время как профессиональные hard skills отходят на второй план [7].

Однако следует заметить, что единого определения и единого подхода к формированию набора soft skills не существует [2]. Наиболее логичной представляется позиция исследователей, которые считают, что при определении того, что такое soft skills, необходимо отталкиваться от контекста и сферы деятельности.

Чаще всего к soft skills относят коммуникативные навыки, управленческие навыки, самоорганизационные навыки, умственные навыки. Однако в работах современных исследователей все чаще появляется мысль о необходимости включения в состав soft skills эмоциональных компетенций.

Термин «эмоциональный интеллект» (Emotional Intelligence Quotient - EQ) начали использовать в начале 1990-х гг. [10]. Эмоциональный интеллект — та- 
E. А. Жигалова. Мягкие навыки в профессиональной деятельности сотрудников правоохранительных органов

кой тип социального интеллекта, который использует способность к мониторингу собственных эмоций и эмоций других людей, для того чтобы различать их и применять данную информацию для управления собственным мышлением и действиями. Авторы утверждали, что люди, обладающие высоким уровнем EQ, способны на быстрый прогресс в определенных областях и эффективное использование своих способностей. Эмоциональная компетентность не является итоговой, конечной характеристикой. Она предусматривает приобретение опыта в условиях человеческого взаимодействия.

К тому же лица с высокой эмоциональной компетентностью более адекватно реагируют на стресс, что важно для лидеров в условиях современной тенденции к изменениям и неопределенности.

В общем виде все soft skills можно разделить на пять групп:

- коммуникативные навыки;

- управленческие навыки;

- самоорганизационные навыки;

- умственные навыки;

- эмоциональная компетенция.

К коммуникативным навыкам относятся навыки проведения переговоров, публичных выступлений, ораторское мастерство, умение налаживать связь с общественностью и прочее.

1. Управленческие навыки содержат навыки:

- публичной деятельности;

- умения работать с другими сотрудниками.

2. Самоорганизационые навыки связаны с:

- управлением временем;

- своим карьерным ростом;

- адекватным самоанализом.

3. Умственные навыки содержат:

- креативное;

- критическое;

- аналитическое;

- тактическое;

- системное;

- логическое мышление.

4. Эмоциональная компетенция нацелена на:

- сбалансирование эмоций и мысленных функций;

- создание положительной эмоциональной атмосферы и ощущение ответственности за выполнение важных для общества задач;

- осознание мотивов поведения оппонентов;

- правильное распознавание эмоциональных сигналов слушателей;

- создание корпоративной культуры для обеспечения эффективной деятельности коллектива [5]. 
Приведенный перечень soft skills может быть скорректирован с учетом конкретной сферы профессиональной деятельности. Рассмотрим это на примере профессиональной деятельности сотрудников правоохранительных органов.

Правоохранительные органы требуют соответствующего взаимодействия с разными людьми в любое время в различных ситуациях. Для этого необязательно применять те навыки, которые получены во время профессиональной подготовки, то есть тут речь идет больше об эмоциональных навыках, которые нужно развивать, чтобы быть действительно эффективными в повседневной работе полицейского, то есть soft skills. Особенности применения мягких навыков полицейскими в том, что их использование должно базироваться на следующих умениях:

- организовывать контакт и организовывать диалог с разными типами людей;

- оказывать влияние и вести эффективные переговоры;

- понятно и убедительно излагать свою точку зрения;

- владеть различными форматами делового общения;

- уметь слушать и слышать то, что до него могут донести другие люди [9].

Если рассматривать данные умения именно с точки зрения навыков, то следует отметить следующие аспекты применения основных из них. В частности эмпатии. Сочувствие к людям, будь то свидетели, жертвы, подозреваемые или обвиняемые, помогает построить связь. Кроме того, эмоциональная связь располагает людей к более открытой передаче информации, которая в дальнейшем может быть использована в ходе проведения оперативно-разыскных мероприятий либо следственных действий.

Невербальная коммуникация. Невербальное общение - это те сигналы, которые мы посылаем выражением лица, жестом или положением тела, что часто имеет гораздо больший вес, чем все слова и переданная информация. Сотрудники полиции должны знать, какие сигналы необходимо использовать, чтобы смягчить конфликт и снять напряжение. Однако тут существует проблема, связанная с таким фактором, что в определенных случаях, вследствие психологических особенностей, человек может неправильно понять подаваемые знаки, что может ухудшить ситуацию.

Активное слушание означает правильное толкование и понимание потребностей других в разговоре. Это ключ для того, чтобы решить конфликт. Как только человек понимает, что его слова важны, он начинает подавать информацию более активно, что располагает к более быстрому и эффективному разрешению конфликтной ситуации либо способствует сбору нужной информации и выяснению обстоятельств происшествия.

Адаптивность. Сотрудники МВД России должны уметь предвидеть, приспосабливаться и преодолевать стоящие перед ними вызовы, чтобы обеспечить выполнение своих обязанностей. Для укрепления доверия населения к сотрудникам полиции последние должны постоянно общаться с гражданами, в том числе проводя профилактические беседы, находить точки соприкосновения, выслушивать их потребности в помощи со стороны правоохранительных органов, выстраивая взаимоотношения с теми, с кем они встречаются на работе каждый день. Вос- 
E. А. Жигалова. Мягкие навыки в профессиональной деятельности сотрудников правоохранительных органов

приятие правоохранительных органов происходит через взаимоотношения с членами общества, должностными лицами и средствами массовой информации.

Критическое мышление и наблюдения. Сотрудники МВД России должны уметь критически мыслить, если они собираются помогать членам сообщества решать проблемы и разрешать конфликты. Способность визуально и эмоционально оценивать ситуацию может спасти жизнь сотрудника и жизни других людей. Лица, ориентированные на детали, являются лучшими наблюдателями, так как они могут выбирать небольшие (но важные) детали.

Разрешение конфликтов. К сожалению, конфликт является огромной частью работы сотрудника правоохранительных органов. Независимо от того, призвана полиция просто реагировать на вызов или предпринимает принудительные действия против отдельного лица, характер работы таков, что неизбежно вызывает конфликт в той или иной степени. Поскольку конфликт сопровождает большую часть работы сотрудника МВД России, жизненно важно уметь этот конфликт решать мирно.

То есть мягкие навыки становятся все более важными для всех сфер профессиональной деятельности. Но необходимость оттачивать и развивать эти навыки, возможно, гораздо более выражена и остра в правоохранительных органах. Поскольку общество требует от них большего сочувствия и понимания, эмоциональный интеллект и мягкие навыки становятся все более важными в подборе и подготовке сотрудников полиции.

Таким образом, можно говорить, что современные исследования компетенций выявили тенденцию смещения акцента c hard skills (твердых профессиональных навыков) на soft skills (мягкие универсальные навыки) для персонала (coтрудников, служащих и т. д.). Сегодня не существует единого подхода к формированию состава soft skills, зато высказывается мнение о целесообразности учета данного контекста во всех в сферах профессиональной деятельности, в том числе и в структуре МВД России.

Лumepamypa

1. Амосов А., Гавкалова Н. Модели публичного администрирования (архетипическая парадигма) // Публичное управление: теория и практика. 2013. Спецвып. С. 6-13. Текст: непосредственный.

2. Россия 2025: от кадров к талантам / В. Бутенко, К. Полунин, И. Котов [и др.] // decanblog. 2017. 6 ноября. URL: http://image-src.bcg.com/Images/Skills_Outline_web_tcm27175469.pdf (дата обращения: 10.01.2021). Текст: электронный.

3. Жмай А. В. Формирование эмоционального интеллекта необходимая составляющая процесса развития soft skills // Рыночная экономика: современная теория и практика управления. 2018 . Т. 17, № 2(39). С. 34-42. Текст: непосредственный.

4. Кравцова Т. М., Солонарь А. В. Понятие и принципы деятельности публичной администрации // Форум права. 2010. № 4. С. 522-525. Текст: непосредственный.

5. Рулиене Л. Н. Развитие «мягких навыков» в непрерывном образовании // Образование через всю жизнь: непрерывное образование в интересах устойчивого развития: материалы XVII Международной конференции / под редакцией В. П. Галенко, Н. А. Лобанова. СанктПетербург, 2019. С. 477-480. Текст: непосредственный. 
6. Чуланова А. Л. Компетенции персонала в цифровой экономике: операционализация soft skills персонала организации с учетом ортобиотических навыков и навыков well-being // Вестник евразийской науки. 2019. № 2. С. 32-47. Текст: непосредственный.

7. Чуланова А. Л. Социально-психологические аспекты управления: эмоциональная компетентность руководителя в структуре soft skills (значение, подходы, методы диагностики и развития) // Науковедение. 2017. Т. 9, № 1. С. 56-64.

8. Чуланова О. Л. Формирование, развитие и коучинг эмоциональной компетентности в управлении персоналом организации: монография. Москва: ИНФРА-М, 2019. 217 с. Текст: непосредственный.

9. Японцев В. Г. Конфликтология и применение адаптивных навыков // Психология в профессии. 2020. № 4. С. 56-62. Текст: непосредственный.

10. Bar-On R. The Bar-On Emotional Quotient Inventory (EQ-i): Rationale, description and summary of psychometric properties // Measuring Emotional Intelligence: Common Ground and Controversy / Ed. by G. Geher. New York: Nova Science Publishers, Inc, 2004. P. 115-145. Текст: непосредственный.

11. Bratcher E. Trend Micro's Austin Offices Inspire Collaboration And Interaction [Electronic resource] // Work Design Magazine. 2018. February 6. Текст: непосредственный.

12. The New Digital World of Work: How HR Will Change in 2016 [Electronic resource]. Available at: https://www.forbes.com/sites/joshbersin/2016/01/29/ten-predictions-for-hr-leaders-in2016-how-the-digital-world-of- work-will- change / \# 6ed9c2975555. Текст: непосредственный.

Статья поступила в редакцию 09.02.2021; одобрена после рецензирования 25.03.2021; принята к публикации 09.04.2021.

\section{SOFT SKILLS IN PROFESSIONAL ACTIVITY OF LAW ENFORCEMENT OFFICERS}

\section{Evgeniya A. Zhigalova}

Researcher,

Research, Editorial and Publishing Department,

East-Siberian Institute of the Ministry of Internal Affairs of Russia

110 Lermontova St., Irkutsk 664074, Russia

razr15@rambler.ru

Abstract. In this day and age performance of professional duties requires not only certain knowledge that is inherent in a particular profession, but also skills that allow using one's own experience most effectively. Soft skills are of particular importance to professionals in all fields, including law enforcement officials. We have considered in detail the factors of using soft skills in the work of law enforcement officers.

Keywords: hard skills; soft skills; professional competencies; professional activity; personal qualities.

For citation

Zhigalova E. A. Soft Skills in Professional Activity of Law Enforcement Officers. Education. Person. Society. 2021; 1: 65-70 (In Russ.).

The article was submitted 09.02.2021; approved after reviewing 25.03.2021; accepted for publication 09.04.2021. 